\section{The Year of ...}

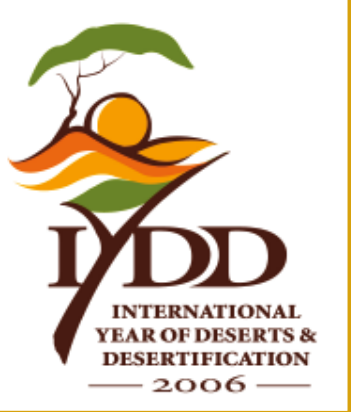

2006-The

International Year

of Deserts and

Desertification

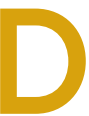

esertification is one of the world's most alarming processes of environmental degradation. The great scope and urgency of this challenge led the United Nations General Assembly to proclaim 2006 as the International Year of Deserts and Desertification. The "year," now already in progress, is intended to raise public awareness of the problem and to help protect the biological diversity of deserts as well as the traditional knowledge of those communities affected by desertification. The primary objective is to profile desertification as a major threat to humanity, reinforced under the scenarios of climate change and loss of biological diversity.

Drylands constitute about 41 percent of the Earth's surface and support more than 2 billion people. Between 10 and 20 percent of drylands are degraded or unproductive. Land degradation affects one-third of the planet's land surface and threatens the health and livelihoods of more than 1 billion people in more than 100 countries. Each year, desertification and drought cause an estimated USD 42 billion in lost agricultural production. The risks of desertification are substantial and clear. Desertification contributes to food insecurity, famine, and poverty and can give rise to social, economic, and political tensions that further promote conflict, poverty, and land degradation.

www.iydd.org

\section{7-2008-}

\section{The International Polar Year}

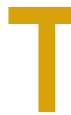
he International Council for Science (ICSU) formally agreed to establish an International Polar Year (IPY) in 2007-2008. It is envisioned that the IPY will be an intense, internationally coordinated campaign of research that will initiate a new era in polar science. IPY 2007-2008 will include research in both polar regions and recognize the strong links these regions have with the rest of the globe. It will involve a wide range of research disciplines, including the social sciences, but the emphasis will be interdisciplinary in its approach and truly international in participation. It aims to educate and involve the public, and to help train the next generation of engineers, scientists, and leaders.

www.ipy.org

\section{8-The \\ International Year of Planet Earth}

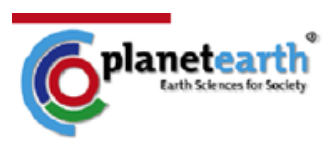

.

he United Nations General Assembly, meeting in New York, has announced that 2008 will be the United Nations International Year of Planet Earth. Related activities will span three years, from 2007 to 2009.

The purpose of the Year of Planet Earth, encapsulated in the tagline "Earth Sciences for Society," is to:

- reduce risks for society caused by natural and human-induced hazards

- reduce health problems by improving understanding of the medical aspects of the Earth sciences

- discover new natural resources and make them available in a sustainable manner

- build safer structures and expand urban areas, utilizing natural subsurface conditions

- determine non-human factors in climatic change

- enhance understanding of the occurrence of natural resources so as to contribute to efforts to reduce political tension

- detect deep and poorly accessible groundwater resources

- improve understanding of the evolution of life

- increase interest in the Earth sciences in society at large

- $\quad$ encourage more young people to study the Earth sciences at the university level

"Around the shores of the Indian Ocean, some 230000 people are dead because the world's governments have not yet grasped the need to use geoscientists' knowledge and understanding of the Earth more effectively," says Eduardo F.J. de Mulder, project leader 
of the Year of Planet Earth and former president of the International Union of Geology and Geophysics. "Yet that knowledge is readily available in the practical experience and publications of some half a million Earth scientists all over the world, a professional community that is ready and willing to contribute to a safer, healthier, and wealthier society if called upon by politicians and decision-makers. The International Year of Planet Earth (2007-2009) aims to contribute to the improvement of everyday life, especially in the less developed countries, by promoting the societal potential of the world's Earth scientists."

\section{www.esfs.org}

\section{Safety Training Program - Call for Applicants}

aking the world a bit safer, safety experts from developing countries have an opportunity to visit and work in plants of IUPAC Company Associates in the industrialized world for a training period of one to three weeks.

The IUPAC-UNESCO-UNIDO Safety Training Program is a Fellowship Program for Safety and Environmental Protection in Chemical, Biotechnological, and Pharmaceutical Production that allows safety experts from developing countries to learn about safety and environmental protective measures by visiting and working in plants of IUPAC Company Associates in industrialized countries. IUPAC, working with the United Nations Educational, Scientific, and Cultural Organization (UNESCO) and the United Nations International Development Organization (UNIDO), has established and maintained the Safety Training Program to promote interactions between developed countries and the developing world to disseminate state-of-the-art knowledge on safety and environmental protection in chemical production.
Each scientist or engineer accepted into the Safety Training Program is assigned to an IUPAC Company Associate in an industrialized country. Accommodation, subsistence, and travel expenses are provided for all trainees.

Successful candidates are professional scientists and engineers who are currently:

- involved at a supervisory or managerial level in chemical companies, government institutions, or scientific institutions

- engaged in aspects of safety and environmental protection in chemical, pharmaceutical, or biotechnological production or in the teaching of these fields

- have the ability to influence safety practices in their places of employment and elsewhere within their home country

Applications are now invited for placement in the 2006 program. For more information, go to

www.iupac.org/standing/coci/safety-program.html
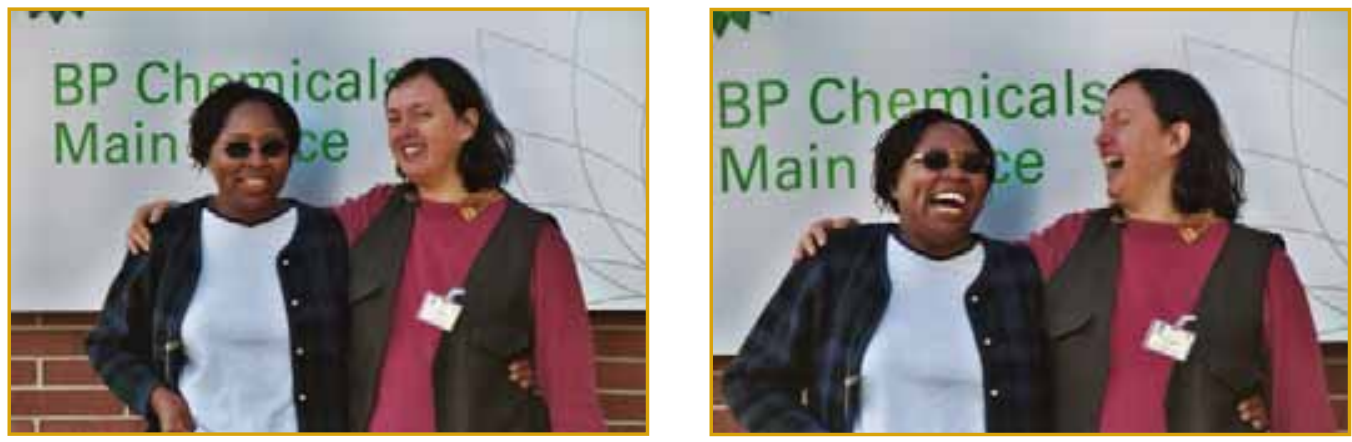

2003 fellows Jane B. Nyakang'o (UNIDO Kenya National Cleaner Production Centre) and Ana Luisa Arocena (CEMPRE Uruguay) seriously enjoying their visit of the BP Chemicals Technology Center in Naperville, Illinois, USA. 